\title{
PROCEDIMENTOS DIDÁTICO-PEDAGÓGICOS NA APRENDIZAGEM DE LEITURA NO AMBIENTE ESCOLAR
}

\author{
Francisco Menezes da Silva ${ }^{1}$
}

RESUMO: O domínio da leitura reflete diretamente na qualidade da aprendizagem. Logo, faz-se necessário refletir sobre a prática leitora em sala de aula como perspectiva de mensura da qualidade do ensino-aprendizagem na escola. Nesse contexto, este estudo buscou refletir, por meio de uma abordagem bibliográfica, acerca da importância dos procedimentos didático-pedagógicos do ensino da leitura nas escolas, à luz de autores como Brasil (1996); Martins (1982); Kleimam (1999); Cagliari (1992); Freitag (1994); Geraldi (1995) e dos Parâmetros Curriculares Nacionais do Ensino Fundamental (2001). Diante disso para o desenvolvimento do gosto e do hábito dos alunos pela leitura, devem-se elucidar momentos lúdicos e prazerosos de forma que sejam utilizados os espaços escolares - como dependências físicas (biblioteca/sala de leitura) - que estimulem a leitura em momentos lúdicos e prazerosos, visto que essa é uma alternativa que pode superar as dificuldades mostradas nas discussões da pesquisa de sobremaneira a atuar na perspectiva da formação de cidadãos e, portanto, na evolução da sociedade.

PALAVRAS -CHAVE: Leitura. Procedimentos didático-pedagógicos. Aprendizagem. Ensino.

\section{PRELÚDIOS INICIAIS}

O Sistema de Avaliação da Educação Básica - SAEB - e os dados do Ministério da Educação - MEC - demonstram em seus resultados anuais que educação no Brasil passa por momentos críticos. Na região amazônica os últimos resultados do SAEB mostram que os alunos têm bastante dificuldade tanto para ler, como para escrever. A ausência dessas habilidades implica em problemas intensificadores de desigualdades no país.

Nesta perspectiva, faz-se necessário refletir, neste estudo, sobre a prática pedagógica do ensino da leitura, bem como sobre como ocorre a transmissão de habilidades de leitura na sala de aula ao se questionar qual importância do ensino da leitura pelo corpo docente aos alunos do ensino fundamental? O trabalho com a leitura é atrativo ou apresenta conteúdos que desenvolvem o senso crítico dos educandos? Como se motiva a leitura na sala de aula? Essas e outras questões são oportunas para ratificar o fracasso dos alunos nos exames e/ou na evolução de uma série para outra.

O debate acerca do ensino da leitura de forma a melhorar a qualidade do ensino aprendizagem dos estudantes da região amazônica se pauta no discurso apresentado por teóricos como Brasil (1996); Martins (1982); Kleimam (1999); Cagliari (1992); Freitag (1994); Geraldi (1995) e dos Parâmetros Curriculares Nacionais do Ensino Fundamental (2001), com a fina-

1 Instituição: Universidade Federal do Pará, Orcid: https://orcid.org/0000-0003-1629-179X, E-mail: franciscosilvass@gmail.com 
lidade de refletir sobre a importância do ensino da leitura a partir das impressões e posicionamento dos professores em relação à aprendizagem cognitiva do corpo discente.

Assim, o objetivo deste estudo foi propor uma reflexão aos sujeitos envolvidos no processo de ensino-aprendizagem a visão da leitura enquanto habilidade de desafios e transformação que uma vez desenvolvida plenamente confere independência e autonomia (PCNs - vol. 02, 2001 p.58).

A fim de garantir o desenvolvimento da competência de leitura, da escrita e de outras habilidades, a escola deve propiciar ao aluno um espaço de formação e informação, no que tange às questões referentes à formação intelectual, pessoal e social na busca de aprimorar o prazer pelo conhecimento. Para tanto, os Parâmetros Curriculares propõem que a escola organize o ensino de modo a instigar no aluno o desenvolvimento de suas capacidades e conhecimentos discursivos e linguísticos conforme seus propósitos e demandas sociais. (PCNsintrodução vol. 02, 2001, p.58/59).

Desta forma, esta pesquisa divide-se em três tópicos, o primeiro refere-se ao conceito de leitura enquanto questão de interpretação, o segundo, aborda os tipos de leitura conforme as ações cognitivas no sujeito, o terceiro tópico, versa acerca dos procedimentos didático-pedagógicos concernentes à leitura, seguido das considerações finais do estudo que denota uma reflexão crítica do processo de ensino-aprendizagem e da importância da leitura para o desenvolvimento dos sujeitos no contexto atual.

\section{LEITURA, UMA QUESTÃO DE INTERPRETAÇÃO?}

A leitura, conforme o interesse individual do sujeito, pode proporcionar reflexões voltadas para os problemas sociais, políticos, educacionais e culturais que em diversificadas vezes instruem os alunos a perceberem e/ou repensarem suas posturas diante da sociedade, haja vista serem objetos e sujeitos do contexto histórico atual. Nesse contexto, dentre os objetivos para o ensino fundamental destaca-se:

LDB 9394/96 (Art.32, I):

O desenvolvimento da capacidade de aprender, tendo como meios básicos o pleno domínio da leitura, da escrita e do cálculo; [...] (grifo meu).

Em virtude dessa afirmação, considera-se oportuno abordar o conceito de leitura enquanto habilidade que potencializa o ato de inferir, refletir e reformular a compreensão com intuito de alcançar um novo estágio cognitivo, ou seja, que haja aprendizagem ao ler e a interpretar um texto ou algo do gênero.

O dicionário Aurélio Júnior da Língua Portuguesa (2011, p.548) define leitura como 1. "Ato de ler ou resultado deste ato"; 2. "Aquilo que se lê". Percebe-se que o conceito do dicionário caracteriza um procedimento solto, isto é, que não esclarece o que venha a ser leitura, tendo em vista o desinteresse daquela num contexto político, econômico, social, cultural e educacional, enquanto problemática que circunda o cotidiano de cada sujeito inserido no ambiente social. Portanto, o norte da abordagem em questão parte do efeito de apreciação do significado da leitura a partir da posição social do sujeito como perspectiva da formação plena do indivíduo para "construir na escola de uma politica de formação de leitores, na qual possam contribuir com sugestôes para desenvolver uma prática constante de leitura que envolva o conjunto da unidade escolar" (PCNs- introdução vol. 02, 2001, p.59). 
Freitag (1994, p.64) reitera que ler significa interpretar o texto, debater o texto, contradizer o texto, desestruturar e recompor o texto no interior do pensamento. Logo, o conceito de leitura extrapola a dimensão da decodificação de símbolos linguísticos, tal como envolve os leitores no contexto real da história, conforme afirma Cagliari em seu livro alfabetização e linguística:

Leitura é uma atividade de assimilação de conhecimentos de interiorização, de reflexão. [...] também tem sua convencionalidade guiada não só pelos elementos linguísticos, mas também pelos culturais, ideológicos, filosóficos, etc. (CAGLIARI 1992, P. 150-151).

No entanto, Geraldi (1995, p.9), concebe leitura enquanto processo de interlocução entre leitor/autor mediado pelo texto e ainda:

Ler não é decifrar como num jogo de adivinhações, o sentido de um texto. É a partir do texto, ser capaz de atribuir-lhe significado, conseguir relacioná-lo a todos os outros textos significativos para cada um, reconhecer nele o tipo de leitura que seu autor pretendia e dono da própria vontade, entregar-se contra ela, propondo outra não prevista (LAJOLO,1982 apud GERALDI,1995, P.91).

A preocupação desses autores em frisar a leitura para além da decifração dos símbolos linguísticos, quer dizer que ler ultrapassa a questão fonética da mera pronúncia da palavra escrita. Limitar-se à leitura de textos críticos filosóficos, literários ou políticos não é suficiente para propiciar aos alunos, mudanças radicais no comportamento social. Todavia, com a intermediação do docente na reflexão desses textos, o aluno pode vir a criar essa consciência social e política da realidade que o cerca, uma vez que a educação é transformadora do fator social e político, quando conscientiza os discentes a participarem da vida em sociedade, para formular uma consciência política do status quo na qual vivem os brasileiros e milhares de pessoas no mundo.

Kleimam (1999, p.13) impera que a compreensão de um texto é um processo que se caracteriza pela utilização de conhecimento prévio: o leitor utiliza o que já sabe, o conhecimento adquirido ao longo de sua vida. Também ao ler um texto, uma criança ou adulto necessitará de conhecimento além da decodificação dos símbolos linguísticos, segundo os Parâmetros Curriculares Nacionais da Língua Portuguesa:

A compreensão da leitura do texto depende necessariamente do conhecimento prévio que o leitor tiver sobre o tema e da familiaridade que tiver construído com a leitura de textos do gênero. [...] muito do fracasso dos objetivos relacionados à formação de leitores e usuários competentes da escrita é atribuído à omissão da escola e da sociedade diante de questão tão sensível à cidadania. (PCN, 2001, P. 32)

Oportunizar a leitura ao aluno, considerando o seu conhecimento de mundo, é mais agradável que simplesmente condicioná-lo a realizar uma leitura mecanizada sem significados de vida. Nessa linha de raciocínio, "ler é uma atividade extremamente complexa e envolve problemas não só semânticos, culturais, ideológicos, filosóficos, mas até fonético" (CAGLIARI, 1992, P.149).

\section{O TRABALHO COM OS DIVERSOS TIPOS DE LEITURA}

Para desenvolver no campo pedagógico leituras críticas sobre os problemas sociais, econômicos e políticos que envolvem um país, estados, municípios e consequentemente o próprio 
bairro em que os alunos residem, há tipos de leituras que podem sim, auxiliar os professores em sala de aula, entre as quais está a falada, a ouvida e a visual, concomitantemente a esses tipos de leitura, acrescem-se o melhoramento dos aspectos sensorial, emocional e racional do sujeito.

Leitura falada, segundo Cagliari (1995), um texto escrito pode ser decifrado e decodificado por alguém que traduz o escrito numa realização de fala. Esse tipo de leitura ocorre mais comumente nos primeiros anos de escola, no trabalho de certos profissionais, em raras situações na maioria das pessoas.

Em geral, os sujeitos não leem em voz alta fora da escola. E quando algumas pessoas são solicitadas a ler, envergonham-se, dão desculpas e afirmam que não sabem ler direito. Para Cagliari (1995), isso ocorre porque a leitura oral, falada, é vista geralmente, de maneira preconceituosa pela sociedade, isto é, assume a forma de realização plena da modalidade padrão no seu nível mais formal, isto é o padrão culto da língua.

Ouvir histórias também é uma forma de ler. A diferença entre ouvir a fala e ouvir a leitura está em que a fala é produzida espontaneamente, ao passo que a leitura está onde a fala é produzida de maneira espontânea. Entretanto, foneticamente as duas atividades são muito semelhantes com relação ao processamento.

Uma leitura equivale a ler com os olhos, a única diferença reside no canal pelo qual a informação do texto é conduzida ao cérebro, mesmo que a leitura seja uma habilidade aprendida e desenvolvida a partir das relações sociais e dentro de um conjunto, a prática mais frequente na sala de aula (inclusive nas universidades) é a leitura silenciosa visual. Esta, para a escola e para os professores têm múltiplas finalidades:

\footnotetext{
Hoje até as poesias são lidas na solidão de cada um, e ninguém estranha que uma forma linguística que nasceu para ser ouvida, por suas características rítmicas e melódicas, não seja a mais usada em sua plenitude. É quase como um músico que lê uma partitura e imagina a música. Ler uma peça de teatro não é o mesmo que vê-la encenada. São dois tipos diferentes de leitura. Nem sempre a leitura visual silenciosa é a mais adequada para certos textos, que foram feitos com a intenção de serem lidos oralmente ou ouvidos (CAGLIARI 1992, P.156).
}

Alguns educadores adotam esta metodologia com o objetivo de empreender um melhor resultado, outros a usam simplesmente para manter os alunos sentados e em silêncio, mesmo quando a leitura se realiza desse modo, as questões ali tratadas carecem passar por uma plataforma de diálogo entre os leitores para uma internalização das informações. Os alunos aprendem a problematizar coletivamente as informações e ao longo de sua vida escolar eles desenvolvem a competência para fazer isso sozinho.

$\mathrm{Na}$ leitura falada, ouvida ou visual poder-se-á acrescentar os seguintes níveis básicos de leitura, o sensorial, o emocional e o racional, que conforme Martins (1986) a leitura é dinâmica e circunstancial, consequentemente esses três níveis são inter-relacionados, senão simultâneos, mesmo sendo um ou outro privilegiado, segundo a experiência, expectativas, necessidades e interesses do leitor e das condições de contexto geral em que se insere.

Destaca ainda Martins (1982), que a leitura sensorial, a visão, o tato, o gosto e o olfato podem ser apontados como os referenciais mais elementares do ato de ler, uma vez que através dos sentidos são percebidos detalhes na leitura que edificam a formação da personalidade, 
do caráter, assim como do certo e do errado inerente às faculdades mentais e psicológicas do sujeito, contudo, na leitura sensorial o que importa é a resposta física que cerca a impressão em nossos sentidos, a fim de ligar as emoções e a razão, sendo que, às vezes, pregam-nos peças, perturbam, surpreendem ou mudam o percurso de leitura em virtude de tais sensações:

\footnotetext{
Assim, quando uma leitura - seja do que for - nos faz ficar alegres ou deprimidos, desperta a curiosidade, estimula a fantasia, provoca descobertas, lembranças - aí então deixamos de ler apenas com os sentidos Para entrar em outro nível de leitura o emocional (MARTINS, 1982, p.48).
}

Um fator que se contrapõe à leitura emocional é a leitura elitizada que em nome da norma culta lê racionalmente. Martins ainda reitera que esse nível intelectual enfatiza a preeminência dos fenômenos intelectuais sobre a vontade. Essa leitura racional apresenta um caráter eminentemente reflexivo e dinâmico, porém na leitura racional o leitor centra todas as atenções no texto, objetiva questionamentos, procura dialogar e entender o texto. Consequentemente, a fim de compreender o texto lido ou objeto estudado, qualquer leitor necessitará das leituras anteriores, emocional e sensorial, visto que suas capacidades mentais e psicológicas o levarão a usufruir desses recursos numa complexa cadeia de formulação, de sentido e de juízo de valores com intuito a contemplar o significado do texto.

Nesse contexto, podem-se perceber, portanto, duas concepções de leitura aqui denotadas como: a) behaviorista-skinneriana, que se processa por meio de uma decodificação mecânica de signos linguísticos, por meio de aprendizado estabelecido a partir do condicionamento estímulo-resposta; b) concepção cognitivo-sociológica, criada pela compreensão abrangente, cuja dinâmica envolve componentes sensoriais, emocionais, intelectuais, fisiológicos, neurológicos, bem como culturais, econômicos e políticos.

\section{PROCEDIMENTOS DIDÁTICO-PEDAGÓGICOS CONCERNENTES À LEITURA}

Para que os alunos possam apreender o tema abordado bem como tirar suas próprias conclusões interpretativas ou intelectivas do texto lido, faz-se necessário que se promova na sala de aula de forma didática momentos agradáveis de leitura. Nesse sentido, busca-se explicar à luz dos PCNs da Língua Portuguesa (1998) explicitar as leituras: autônoma; colaborativa; leitura em voz alta pelo professor e a leitura de escolha pessoal com intuito de orientar futuros leitores.

\section{Conforme PCNs:}

\section{Leitura autônoma}

A leitura autônoma envolve a oportunidade de o aluno poder ler, de preferência, silenciosamente, textos para os quais já tenham desenvolvido uma certa proficiência. Vivenciando situações de leitura com crescente independência da mediação do professor, o aluno aumenta a confiança que tem em si como leitor, encorajando-se para aceitar desafios complexos. ${ }^{2}$

Neste modelo de leitura ressalta-se que os alunos precisam de concentração e o ambiente na sala de aula deve estar em harmonia com a respectiva leitura, ou seja, o silêncio precisa prevalecer, pois, assim o aprendizado aumentará e fluirão reflexões mais aguçadas no momento do debate mediado pelo professor em sala de aula.

2 PCNs, 1998, P. $72 / 73$. 


\title{
Leitura colaborativa
}

Caracteriza uma atividade em que o professor lê o texto junto à classe e, durante a leitura, questiona os alunos sobre os índices linguísticos que dão sustentação aos sentidos atribuídos. [...] A possibilidade de interrogar o texto, a diferenciação entre realidade e ficção, a identificação de elementos que veiculem preconceitos de recursos persuasivos, a interpretação de sentido figurado, a inferência sobre a intenção do autor, são alguns dos aspectos dos conteúdos relacionados à compreensão de textos, para os quais a leitura colaborativa tem muito a contribuir. ${ }^{3}$

A leitura colaborativa é oportuna para que o docente possa levantar questionamentos acerca dos problemas sociais e políticos objetivando a compreensão do texto no sentido mais amplo, ou seja, extrapola os conceitos morfológicos, sintáticos e gramaticais.

\section{Leitura em voz alta pelo professor}

Além das atividades de leitura realizadas pelos alunos e coordenadas pelo professor, há as que podem ser realizadas basicamente pelo professor. ${ }^{4}$

Na prática de leitura em voz alta pelo professor, particularmente nas leituras compartilhadas, facilita a percepção dos alunos, da entonação, do ritmo, da pontuação, enfim, o professor ao ler em voz alta estimula no aluno a habilidade de como se deve ler. Assim sendo, essa prática se torna recomendável no espaço escolar.

\section{Leitura programada}

Trata-se de uma situação didática adequada para discutir coletivamente um título considerado difícil para a condição atual dos alunos, pois permite reduzir parte da complexidade de tarefa, compartilhando a responsabilidade. [...] Os alunos realizam a leitura do trecho combinado para discuti-lo posteriormente em classe com a mediação do professor. ${ }^{5}$

Essa forma de se trabalhar a leitura em sala proporciona condições pertinentes aos alunos na percepção de seus entendimentos, tal como oportuniza dividir textos grandes e com certo grau de complexidade, para que todos discentes possam interagir no momento do debate no interior da sala de aula, mediado pelo professor da classe.

\section{Leitura de escolha pessoal}

\begin{abstract}
São situações didáticas, propostas com regularidade, adequadas para desenvolver o comportamento do leitor, ou seja, atitudes e procedimentos que os leitores assíduos desenvolvem a partir da prática de leitura: formação de critérios para selecionar material a ser lido, rastreamento da obra de escritores preferidos etc. neste caso, o objetivo explícito é a leitura em si, é a criação de oportunidades para a constituição de padrões de gosto pessoal. [...] A partir daí, os alunos escolhem o que desejam ler, toma emprestado o livro (do acervo de classe ou da biblioteca da escola) para ler em casa e, no dia combinado, parte deles relata suas impressões, comenta o que gostou ou não, o que pensou, sugere outros títulos do mesmo autor, tema ou tipo. Dependendo do gênero selecionado, alguns alunos podem preparar, com antecedência, a leitura em voz alta dos textos escolhidos. ${ }^{6}$
\end{abstract}

Instaura-se, então, a democracia na escolha do livro para leitura, entretanto as determinações de execução das mesmas, planejada anteriormente com a turma, devem ser cumpridas

3 PCNs, 1998, P. 72/73.

4 Ibidem.

5 Ibidem.

6 PCNs, 1998, P. 72/73. 
para que os alunos não achem que as estratégias de escolha sejam apenas para passar tempo em sala de aula. Outra alternativa, seria solicitar que os discentes visitassem as bibliotecas públicas da cidade (caso existam) ou bibliotecas de universidade e nelas selecionassem textos de temas mais diversos para que no momento adequado discutissem e refletissem os assuntos abordados, não obstante o ato de pesquisar ser pouco praticado nas unidades de ensino.

Uma diferente maneira de proporcionar momentos de diversão com a leitura é ofertar textos curtos de diversificados gêneros, promovendo desta forma, reflexões imediatas, sobretudo, garantindo que todos tenham acesso aos referidos textos conforme Geraldi ressalta:

\footnotetext{
A leitura de um texto curto (noticiário, crônica, conto, piada, causo, etc.) não exerce uma função aleatória na sala de aula. Com os textos curtos, o professor poderá exercer sua função de ruptura no processo de compreensão da realidade (GERALDI, 1995, p.64)
}

Dentre outras formas de trabalhar a leitura, o educador deve ter em mente objetivos estratégicos para uma boa discussão do texto, pois algumas experiências demonstram que no ato da leitura, os alunos que leem objetivamente discutem, respondem e fazem indagações pertinentes e produzem melhor que em uma leitura aleatória.

É fundamental que a escola possua uma política voltada para fomentar a leitura, de modo que cada profissional compreenda que a tarefa de motivar e desenvolver habilidades de leitura no educando não é tarefa exclusiva do professor de Língua Portuguesa, logo, se todos atuarem nessa perspectiva, a qualidade no ensino-aprendizagem de todas as disciplinas do currículo escolar terá ganhos positivos, haja vista, a qualidade e rendimento da base interpretativa dos alunos nos problemas propostos em todas as áreas do conhecimento que passa, primeiramente, pela leitura, na qual sobressai inferência intelectiva para uma possível análise da questão ou do texto lido.

\section{CONSIDERAÇÕES FINAIS}

Considerando a importância deste estudo para a melhoria da qualidade do ensino nas escolas da região amazônica, enfatizou-se uma reflexão crítica do processo de ensino aprendizagem da transmissão de habilidades de leitura e suas consequências para uma boa interpretação, de forma a visar uma educação para o desenvolvimento integral das habilidades e competências dos estudantes no contexto atual e futuro da região e do país.

Constatou-se que a aprendizagem desta e das novas gerações deve se dar por meio das leituras de livros em todas as multimodalidades e das palavras nas mais diversas dimensões. Logo, destaca-se a importância de se continuar a refletir alternativas para o ensino da leitura em sala de aula, visto que a fundamentação teórica desta pesquisa mostrou que, conforme o tipo e o nível de leitura, surgem maneiras diferentes de se abordar textos e agir sobre eles no ambiente social, a partir de uma compreensão holística da leitura e das sensações despertadas no sujeito de acordo com a intencionalidade do autor. Esclarece-se que a leitura propicia aos discentes, reflexões pautadas em aspectos sociais, econômicos, políticos, culturais e educacionais, numa perspectiva histórica social imbuída na ótica dialética.

Na educação, a leitura desempenha o papel principal no ensino aprendizagem escolar, aguça a compreensão crítica do ser humano nas diversas áreas do conhecimento, desde que seja propiciada de forma intencional. Considera-se ainda que para desenvolver o gosto e o 
hábito dos discentes pela leitura, torna-se imperioso proporcionar momentos lúdicos e prazerosos em sala de aula, bem como maximizar o uso das dependências da escola com intuito de proporcionar outros lugares para ler, fora da sala de aula, especialmente, a biblioteca da escola.

Torna-se salutar, a escola motivar e despertar a vontade de ler nos discentes, a fim de estimulá-los a serem leitores-escritores do mundo. Para tanto, o espírito coletivo deve superar o individualismo no cotidiano da escola a partir do compromisso de todos os educadores com a educação das crianças, adolescentes, jovens e adultos para o desenvolvimento da leitura e consequentemente da interpretação e escrita dos mais variados gêneros textuais, tal como propõem os PCNs, com intuito de que todos obtenham sucesso e eficácia nas interpretações de textos escritos, analogamente, nas interpretações dos acontecimentos sociais e na transformação da sociedade.

\section{DIDACTIC-PEDAGOGICAL PROCEDURES IN LEARNING READING IN THE SCHOOL ENVIRONMENT}

ABSTRACT: The domain of reading directly reflects on the quality of learning, so it's necessary to reflect on the practice of this in the classroom as a perspective of measuring the quality of teaching-learning at school. In this context, this study sought to reflect, through a bibliographic approach, on the importance of didactic-pedagogical procedures for teaching reading in schools, in the light of authors such as Brasil (1996); Martins (1982); Kleimam (1999); Cagliari (1992); Freitag (1994); Geraldi (1995) e dos Parâmetros Curriculares Nacionais do Ensino Fundamental (2001). Given this, for the development of the students' taste and habit for reading, playful and pleasurable moments should be elucidated so that school spaces are used - as physical dependencies (library / reading room) - that encourage reading in playful moments and pleasurable, since this is an alternative that can overcome the difficulties shown in the discussions of the research to act in a perspective of the formation of citizens and, therefore, in the evolution of society.

KEYWORDS: Reading. Didactic-pedagogical procedures. Learning. Teaching

\section{REFERÊNCIAS}

BRASIL. LDB 9.394/96. In. SAVIANI, Demerval. A nova lei da Educação: trajetória, limites e perspectivas. $5^{\text {a }}$ ed. Campinas, São Paulo: Autores Associados, 1999.

BRASIL. Parâmetros Curriculares Nacionais: Introdução aos Parâmetros Curriculares Nacionais, Brasília: MEC/ SEF, 1997.

BRASIL. Parâmetros Curriculares Nacionais: Terceiro e quarto ciclo do Ensino Fundamental: Língua Portuguesa Brasília: MEC/ SEF, 2001.

CAGLIARI, Luiz Carlos. Alfabetização e Linguística. 4a Ed. São Paulo, Editora Scipione, 1992 (série Pensamento e Ação no magistério).

FREIRE, Paulo, Pedagogia da Autonomia: Saberes necessários à prática Educativa. São Paulo: São Paulo: Paz e Terra, 1996.

FREITAG, Bárbara. O indivíduo em formação. 3 ed. São Paulo: Cortez, 1994.

GERALDI, João Wanderley (org.) O texto na sala de aula. - 3 ed. São Paulo: Ática 2005.

KLEIMAN, Ângela. Oficina de leitura: teoria e prática. $6^{\text {a }}$ ed. Campinas - São Paulo: Pontes, 1998.

Texto e leitor: aspectos cognitivos da leitura. Campinas - são Paulo: pontes, 1989.

MARTINS, Maria Helena. O que é leitura. 19ª Ed. São Paulo. Editora Brasiliense, 2006. (Coleção primeiros passos;74). 